\title{
Aksiller Hidradenitis Suppurativanın Cerrahi Tedavisinde Torakodorsal Arter PerforatörFlep (TDAP) İle Rekonstrüksiyon Deneyimlerimiz
}

\author{
Zülfükar Ulaş Bali, Yavuz Keçeci \\ Manisa Celal Bayar Üniversitesi, Tıp Fakültesi Plastik Rekonstrüktif ve Estetik Cerrahi Anabilim Dalı Manisa, \\ Türkiye \\ email: zulasbali@gmail.com,yavuz.kececi@gmail.com \\ Orcid: 0000-0001-6894-3900 \\ Orcid: 0000-0002-8915-8706 \\ *Sorumlu Yazar / Corresponding Author: Sorumlu Yazar: Zülfükar Ulaş Bali
}

\author{
Gönderim Tarihi / Received: 30.09.2019 \\ Kabul Tarihi / Accepted: 23.12.2019 \\ DOI: $10.34087 /$ cbusbed.626342
}

Hidradenitissuppurativa tekrarlayan abse, fistül ve skar oluşumu ile karakterize, apokrin bezlerin kronik enflamasyonudur.Kasık, perineal ve perianal bölgelerde ortaya çıkar. Etyolojisindefoliküllerin tıkanması sorumlu tutulmaktadır. Şiddetli olmayan olgularda, antibiyotik, retinoikasit ve hormonoterapi tercih edilebilir. Cerrahi eksizyon tedavide altın standarttır. Bu çalışmada, aksillerhidraadenitissupurativa olgularında cerrahi eksizyon vetorakodorsal arter perforatorflep(TDAP) ile rekonstrüksiyon yapılan olgularımız paylaşılacak, sonuçlar değerlendirilecek ve deneyimlerimiz aktarılacaktır.

Anahtar Kelimeler: Hidraadenitissupurativa, Torakodorsal Arter Perforatorflep.

\begin{abstract}
Hidradenitis suppurativa is a chronic inflammatory infection of the apocrine glands characterized by a recurrent abscess, fistula, and scarring. It occurs in the inguinal, perineal and perianal regions. Follicular occlusion is considered in the etiology. Medical treatment which includes systemic antibiotics, retinoic acid, and hormone therapy may be preferred in non-severe cases. Surgical excision of the affected tissue is the criterion standard treatment. The study aimed to evaluate the results of the use of pedicled thoracodorsal artery perforator flap as a method of reconstruction for axillary effect results from wide surgical excision as a line of treatment for hidradenitis suppurativa of the axilla.
\end{abstract}

Keywords: Hydraadenitissuppurativa, Thoracodorsalarteryperforatorflap.

\section{Giris}

Hidradenitissuppurativa (HS) cilt ve ciltaltı yağlı dokunun kronik, tekrarlayıcı, inflamatuar bir hastalı̆ olup görülme sıklığg kadınlarda erkeklere oranla dört kat fazladır(1-2).Hastalık ilk olarak 1839 da Velpeau tarafindan tanımlanmış, apokrin ter bezlerinden kaynaklandığı ise ilk olarak AristideVerneuil tarafından bildirilmiştir(3). Son çalışmalar HS'nin kıl folikülü ve sebaseöz bez kanallarının tıkanması ile ortaya çıktığını göstermektedir. Ölü cilt hücreleri ve apokrin bezden gelen materyal önce folikül kanalında akımı yavaşlatır ve sebaseöz bezden gelen sebumla birleşerek tıkaç oluşturur. Tıkaç ise apokrin bez drenajını engeller ve lokalirritasyona neden olur. Daha sonra bakteriler lokalinflamatuar yanitı tetikleyerek enfeksiyon gelişimine yol açarlar. Hastalık apokrin bezlerin bulunduğu aksiller, perineal ve perianal bölgelerde ve genellikle puberteden sonra ortaya çıkar. Ağrılı, kronik ve tekrarlayıcı bir hastalıktır(4). Tedavi semptom ve enfeksiyonun dercesine göre uygulanır. Şiddetli olmayan olgularda, topikal ve sistemik antibiyotikler, östrojen/progesteron oranı yüksek oral kontraseptifler(5),tnf alfa inhibitörleri(6),radyoterapi(7), lazer(8), kriyoterapi(9) tedavileri kullanılabilir. Ancak özellikle ileri evre ve tekrarlayan olgularda altın standart tedavi cerrahidir.

$\mathrm{Bu}$ çalışmada, aksiller HS için geniş cerrahi eksizyon yapılan ve oluşan defektinrekonstrüksiyonunda pediküllütorakodorsal arter perforatör (TDAP) flep kullandığımız hastalarla ilgili deneyimlerimizi, tekniğin olumlu ve olumsuz yönleri ile birlikte tartışmayı amaçladik.

\section{Materyal-Metod}

Bu çalışmaya Mart 2017-Aralık 2018 tarihleri arasında, aksiller HS nedeniyle cerrahi yapılmış ve TDAP flep ile rekonstrükte edilmiş 8 hasta dahil edildi. Hastaların yaş aralığ 19 ile 52(ortalama 40) arasında idi. Çalışma,Hurleyevrelemesine göre(10) evre 2 ve evre 3 hastalardan oluşturuldu (FIGURE 1) . Evre 1 hastalar, cerrahi tedaviyi kabul etmeyen hastalar, donör alanı daha önceki bir işleme bağlı kullanılamayacak olan 
hastalar, majör bir cerrahiyi kaldıramayacak olan hastalar çalışmaya dahil edilmedi. Ameliyat öncesi akıntı olan hastalara 2 hafta antibiyotik verildi. Ameliyat sonras1, 10 gün boyunca, kol yaklaşık 30 derece abduksiyonda ve gövde eleve olacak şekilde pozisyon önerildi. Hastalar ortalama 5 gün hastanede kald1.

\subsection{Cerrahi Teknik}

Hasta lateraldekübit pozisyonunda olacak şekilde ameliyata başlandı. Batikon ile boyundan SİAS a kadar tüm alan temizlendi. İlk olarak el doppleri ile torakodorsal arterin perforaörleri işaretlendi. Daha sonra eksizyona başlandı. Tüm fistüllerin çıkartılması amaciyla HS olan alana 1cc metilen mavisi damlatıldı. Metilen mavisi ile boyanan tüm sinüs ve fistüller eksize edildi (FIGURE 2). Oluşan defektinvertikal ve transvers düzlemde ölçümleri yapıldı.

Posterioraksiller çizginin $8 \mathrm{~cm}$ aşşağı $1 \mathrm{~S}$ ve latisimusdorsi kasının lateral sınırının $2 \mathrm{~cm}$ arka tarafının kesişme noktası işaretlendi $\mathrm{Bu}$ nokta torakodorsal damarların kasa giriş noktası olarak kabul edildi. Flep çizimi bu noktayı ve el doppleri ile işaretlenen perforatörleri içine alacak şekilde yapıldı. Flep boyutları transvers düzlemde defektlateral-medial boyuna eşit, vertikal düzlemde defekt üst-alt sınırından $2 \mathrm{~cm}$ uzun olacak şekilde planlandı. Flepinsizyonuna alt sınırdan başlandı. El-dopleri ile işaretlenen perforatör bulunduktan sonra medialinsizyone geçildi.

Flepmedialindenlatissimusdorsi kasının lateral sınırına ulaşıldı. $\mathrm{Bu}$ alanda bulunan torakodorsal damarlar ile perforatör arasında titiz bir diseksiyon yapıldı. Flep in diğer tarafları da insize edildi ve tamamen kas üzerinde perforatörü ile birlikte serbestlendi. Perforatörün boyunun pedikül olarak yeterli olmadığ 2 hastada, torakodorsal damarlar perforatörün çıktığı yerin distalinden bağlandı. Böylece pedikül uzatılarak defekt kapatıldı (FIGURE 3). Bu işlem sırasında torakodorsal sinirler görüldü ve korundu. Verici saha tüm hastalarda primer kapatıldı.

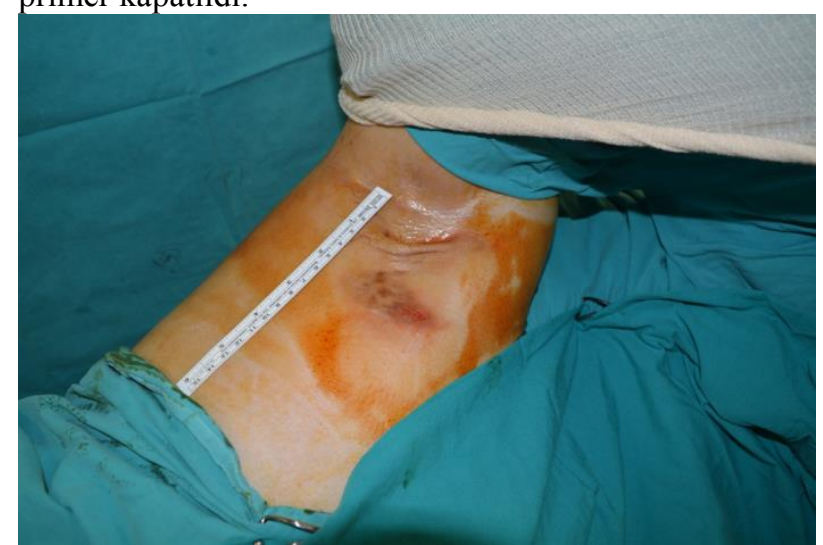

Figure 1

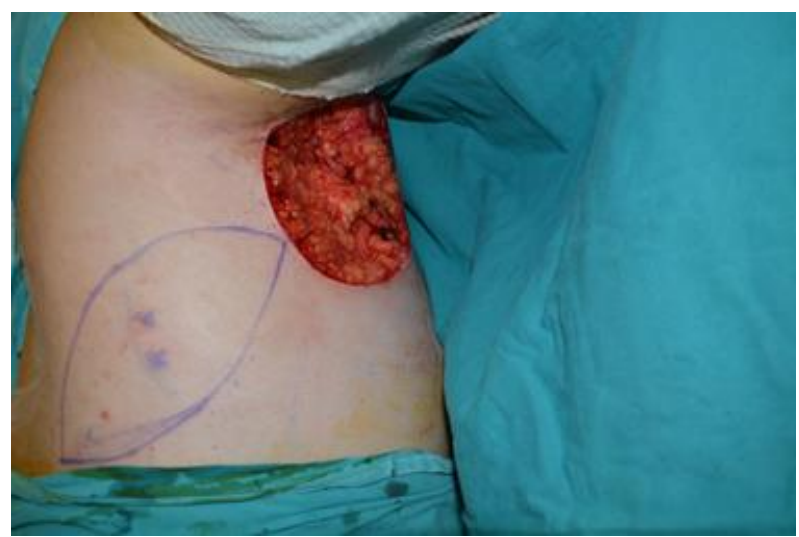

Figure 2

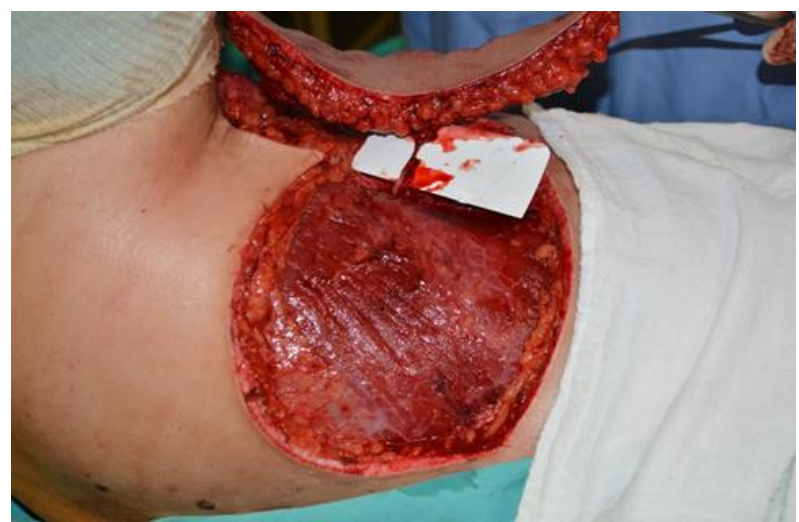

Figure 3

\section{Bulgular}

Bu çalışmaya yaş aralığı 19-52(ortalama 40) olan 8 hasta (8 erkek) dahil edildi. Hastaların ortalama takip süresi 18 ay (9-29 ay) idi. Tüm hastalar da tek taraflı tutulum vard1. Defekt boyutları 8x6 cm ile 16x12 cm aralığında ölçüldü. Geniş eksizyon ve TDAP flep ile onarım ortalama $150 \mathrm{dk}(+-30 \mathrm{dk})$ sürdü. Ameliyat sonrası hiçbir hastada total veya parsiyel nekroz görülmedi. 2 hastada donör sahada seroma izlendi ve aspirasyon+baskılı pansuman ile tedavi edildi. Hastaların 2 sindedonör sahada hipertrofikskar oluştu ve silikon blok ile kısmen düzeltildi. Bir hastada kol abduksiyonunda kısıtlılık (yaklaşı 120 derece abduksiyon) oluştu. Bu hastaya z plasti ile abduksiyon açıklığının arttırılması planlandı ancak hasta istemedi. Diğer 7 hastada geç dönemde kabul edilebilir fonksiyonel ve estetik sonuçlar elde edildi (FIGURE 4).

\section{Tartışma}

Aksillerdefektlerin tedavisinde, greft, lokal ilerletme ve rotasyon flepleri, perforatorflepler, serbest flepler kullanılmaktadır. Aksillerhidraadenit tedavisinde kritik nokta geniş eksizyon yapılmasıdır, çünkü sınırlı eksizyon yapılan vakalarda nüks oranları yüksektir(11). Geniş eksizyon yapılması ile oluşan geniş defektinrekonstrüksiyonu zorlaştırmaktadır. 


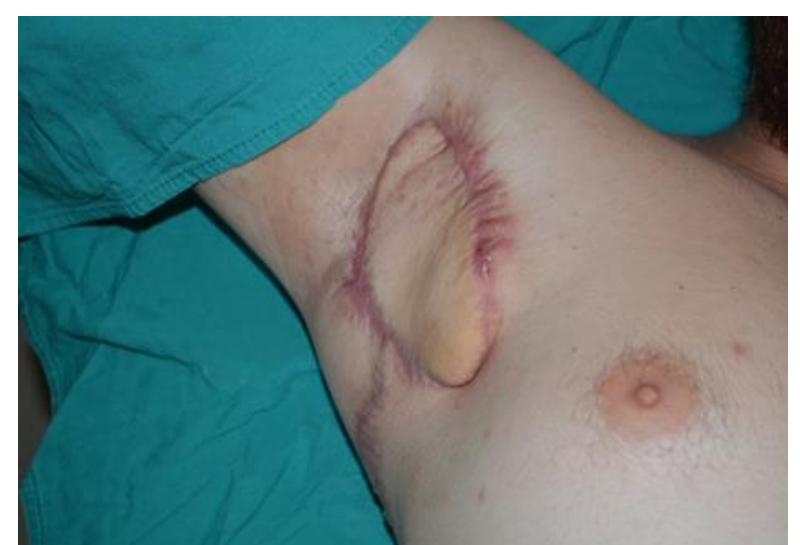

F1gure 4

Aksillerdefektisekonder iyileşmeye bırakmanın sonucu genellikle kontraktür ve kolda hareket kısitlılığı ile sonuçlanmaktadır. Bu bölgenin rekonstrüksiyonu için greft kullanılmasının avantajı, defekt ne kadar genişlikte olursa olsun kısmi kalınlıkta greft ile kapatılabilecek olmasıdır. Ancak greft ile rekonstrüksiyon sonrası da kontraktür oranları yüksektir. Ayrıca aksiller bölgede damar sinir yapıları ortaya çıkmış ise, greftlee yapabilmek için granülasyon dokusunun oluşmasını beklemek gerekir. Buda ikinci bir ameliyat ihtiyacını doğurur. Watson ve arkadaşlarının yaptığı 72 hastalık çalışmada reoperasyon oranları değerlendirilmiştir. Greft ile onarılan hastalarda \%13, flep yapılan hastalarda \%19, primer kapatılan hastalarda \%54 oranında hastalar tekrar ameliyata alınmıştır(12). Mehdizadeh ve arkadaşlarının yaptığı çalışmada nüks oranları deerlendirilmiş ve primer kapatılan hastalarda $\% 15$, flep ile kapatılan hastalarda $\% 8$, greft ile kapatılan hastalarda $\% 6$ oranlarında nüks saptanmıştır(13). Kısmi kalınlıkta greft ile kıl kökleri ve apokringlandlar olmadan bölgeye doku aktarımı gerçekleştirilmektedir. Buda nüks oranlarının kısmi kalınlıkta defekt ile onarılan hastalarda düşük olmasını açıklamaktadır.

Bizim flep ile onarım yaptığımız hastalardan yalnızca 1 inde (\%12.5) tekrar ameliyat ihtiyacı olmuştur. Hastalarımızın ortalama 18 aylık takiplerinde nüks saptanmamıştır. Bu da TDAP flepin bulunduğu bölgede kıl folikülü ve ter bezlerinin az olması ile açıklanabilir.

Salvatore D' Arpa ve arkadaşları bazı durumlarda serbest doku naklinin gerekliliğini vurgulamıştır. Çift taraflı, TDAP flep kullanıldığında donör sahanın primer onarılamayacağı olgularda, karnı uygun hastalarda derin inferiorepigastrik arter perforatorflepile başarılı sonuçlarını sunmuşlardır(14). Ancak serbest doku aktarımlarının, ameliyatın uzun zaman alması, hastanede yatış süresinin uzaması, deneyim gerektirmesi gibi dezavantajları vardır.

Random veya fasyokutanözlokalflepler kullanılmıştır. Ancak bu flepler geniş eksizyon gerektiren HS olgularında defekti kapatmak için yeterli değildirler.

Aksillerdefekti kapatmak için pektoralis majör(15) ve farklı lokal ve serbest kas fleplerikullanılmıştır. Ancak kas fleplerinde alıc sahada fonksiyon kaybı ve inset sonrası aksilladabulky olasılığı yüksektir.

TDAP flep, renk uyumu, ve başarılı fonksiyonel sonuçları nedeniyle aksiller HS tedavisinde altın standarttır(16). Olumsuz yanları ise daha dikkatli ve titiz bir diseksiyon gerektirmesi, buna bağlı olarakda ameliyat süresinin uzamasıdır. Ayrıca flepte nekroz oluşması riskine bağlı ikinci bir planlama yapılması gerekebilir.

\section{Sonuç}

Hidradenitissüpürativa tedavisi zor bir süreçtir. Evre 2-3 hastalarda geniş cerrahi eksizyon yapılması gerekir. Hastalığın nüksünün azaltılması için geniş eksizyon yanında rekonstrksiyonda kullanılan dokunun özellikleri de önemlidir. TDAP flep ile rekonstrüksiyonda, k1l folikülü ve ter bezlerinin az olamasına bağlı nüks oranları düşüktür.Renk-kalınlık uyumu, başarılı fonksiyonel sonuçları, verici alanda fonksiyon kaybı olmaması nedeniyle bu bölge rekonstrüksiyonunda kullanılabilecek en önemli seçeneklerden biridir.

\section{Kaynaklar}

1. Shah N. HidradenitisSuppurativa: A Treatment Challenge. AmFamPhysician. 2005;72:1547-52.

2. Kagan RJ, Yakuboff KP, Warner P, Warden GD Surgicaltreatment of hidradenitissuppurativa: a 10-year experience. Surgery. 2005;138:734-40; discussion 740-1.)

3. Soldin MG, Tulley P, Kaplan H, Hudson DA, Grobbelaar AO. Chronicaxillaryhidradenitis--theefficacy of wideexcisionandflapcoverage. Br J PlastSurg 2000;53:434-6.

4. Adnan İşgör .HidradenitisSüppürativa. AnkemDerg 2011;25(2):121-124

5. Shah N. Hidradenitissuppurativa: a treatmentchallenge, AmFamPhysician 2005;72(8):1547-52. PMid:16273821

6. Delage M, Samimi M, Atlan M, Machet L, Lorette G, Maruani A. Efficacy of infliximabforhidradenitissuppurativa: assessment of clinicalandbiologicalinflammatorymarkers, ActaDermVenereol 2011;91(2):169-71. PMid:21384087

7. Fröhlich D, Baaske D, Glatzel M. Radiotherapy of hidradenitissuppurativa-stillvalidtoday? StranlentherOnkol 2000;176(6):286-9. PMid:10897256

8. Uslu M, Topyıldız H. HidradenitisSupurativada Lazer ve Yoğun Işı Tedavileri. Türkiye Klinikleri Kozmetik Dermatoloji Özel Sayıs1, Sayfa 40-47

9. Bong JL, Shalders K, Saihan E. Treatment of persistentpainfulnodules hidradenitissuppurativawithcryotherapy, ClinExpDermatol 2003;28(3): 241-4. http://dx.doi.org/10.1046/j.13652230.2003.01238.x PMid:12780702)

10. Hurley HJ. Axillaryhyperhidrosis, apocrinebromhidrosis, hidradenitissuppurativa, andfamilialbenignpemphigus: a surgicalapproach. In: Roenigk RK, Roenigk HH, eds. DermatologicSurgery. New York: MarcelDekker; 1989:729739.

11. Farrell AM, Randall VA, Vafaee T, et al. Finasteride as a therapyforhidradenitissuppurativa. $\mathrm{Br} \quad \mathrm{J}$ Dermatol. 1999;141:1138-1139.

12. Watson JD. Hidradenitissuppurativa - a clinicalreview. Br J PlastSurg. 1985;38: 567-569.

13. Mehdizadeh A, Hazen PG, Bechara FG, et al. Recurrence of hidradenitissuppurativaaftersurgicalmanagement: systematicreviewand meta-analysis. J AmAcadDermatol. 2015;73(5 Suppl 1):S70-S77.

14. D’Arpa, S.,Pignatti, M., Vieni, S., Muradov, M., Blondeel, P., \&Cordova, A. (2019). TheThinbilateralandbipedicled DIEAP flapforaxillaryreconstruction in hidradenitissuppurativa.

HandchirMikrochirPlastChir doi:10.1055/a-0881-9646. 
15. Freedlander E, Lee K, Vandervord JG. Reconstruction of theaxillawith a pectoralismajormyocutaneousislandflap. Br J PlastSurg. 1982;35:144-146

16. Marcelli S, Marchesi A, Parodi PC1 et al. PedicledThoracodorsalArteryPerforatorandMuscleSparingLatissimusDorsiFlaps

theAxillaryReconstructionAfterHidradenitisSuppurativaExcis ion: FunctionalandAestheticIssues. AnnPlastSurg 2018; 81 (6): 694-701

http://edergi.cbu.edu.tr/ojs/index.php/cbusbed isimli yazarın CBU-SBED başliklı eseri bu

Creative Commons Alınt1-Gayriticari4.0 Uluslararası Lisansı ile lisanslanmıştır.

(c) (1) (8) 